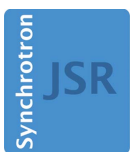

JOURNAL OF SYNCHROTRON RADIATION

ISSN 1600-5775

Received 27 November 2019

Accepted 20 February 2020

Edited by M. Yamamoto, RIKEN SPring-8 Center, Japan

Keywords: macromolecular crystallography; sample changers; high-throughput; cryogenic sample handling.

Supporting information: this article has supporting information at journals.iucr.org/s

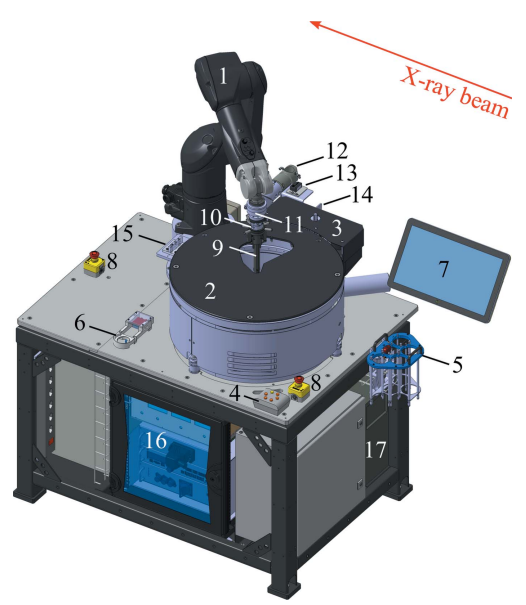

C 2020 International Union of Crystallography

\section{The TELL automatic sample changer for macromolecular crystallography}

Isabelle Martiel,* Dominik Buntschu, Nathalie Meier, Alexandre Gobbo, Ezequiel Panepucci, Roman Schneider, Peter Heimgartner, David Müller, Kevin Bühlmann, Mario Birri, Jakub W. Kaminski, James Leuenberger, Vincent Oliéric, Wayne Glettig and Meitian Wang*

Paul Scherrer Institute, Forschungsstrasse 111, 5232 Villigen, Switzerland.

*Correspondence e-mail: isabelle.martiel@psi.ch, meitian.wang@psi.ch

In this paper, the design and functionalities of the high-throughput TELL sample exchange system for macromolecular crystallography is presented. TELL was developed at the Paul Scherrer Institute with a focus on speed, storage capacity and reliability to serve the three macromolecular crystallography beamlines of the Swiss Light Source, as well as the SwissMX instrument at SwissFEL.

\section{Introduction}

With the advent of fast X-ray detectors and the development of beamline automation, sample exchange has become a limiting step at macromolecular crystallography (MX) beamlines (Grimes et al., 2018). High-throughput projects, such as fragment-based screening campaigns, may involve the unattended data collection of over 200 crystals in a typical $8 \mathrm{~h}$ beam time shift (Collins et al., 2018). Therefore, the automatic sample changers of today need to feature high speed, high storage capacity, as well as high reliability. Other important aspects are minimum maintenance and the control of ice contamination inside the cryogenic storage dewar (Papp, Felisaz et al., 2017).

As a further step in this evolution of MX sample changers (Table 1), a sample-exchange system named TELL (highthroughput enabling large-capacity sample loader) has been developed at the Paul Scherrer Institute. TELL is in use or being deployed at each of the four goniometer-based MX measurement stations at both the Swiss Light Source and SwissFEL (Figs. S1-S4 of the supporting information). Such development allows for a modular construction, build-up of in-house expertise, faster problem solving and custom improvement possibilities.

\section{The TELL sample changer}

\subsection{Overview}

The main components of TELL are a support table, a TX60L or TX2-60L six-axis robotic arm (Stäubli AG, Pfäffikon, Switzerland) with motions programmed in VAL3, a cryogenic sample storage dewar (see next section), and automatically exchangeable grippers such as the SG-1 cryogenic gripper (suna-precision $\mathrm{GmbH}$, Hamburg, Germany). All components of TELL are shown in Fig. 1. The cycle time for a sample exchange at the X06SA-PXI beamline is 
Table 1

Existing sample changer systems at MX synchrotron beamlines.

For commercial systems, the supplier is mentioned. For up-to-date information about availability at a specific beamline, refer the beamline staff or to http://biosync.sbkb.org/.

\begin{tabular}{|c|c|}
\hline Sample changer system & Reference \\
\hline \multicolumn{2}{|l|}{ Multi-axis industrial robots } \\
\hline Stanford Automated Mounter & Cohen et al. (2002); Russi et al. (2016) \\
\hline G-Rob (Nat X-ray) & Jacquamet et al. (2004); le Maire et al. (2011) \\
\hline CATS (Irelec) & Ohana et al. (2004); Jacquamet et al. (2009) \\
\hline ISARA (Irelec) & $\begin{array}{l}\text { https://www.irelec-alcen.com/en/synchrotrons/X-ray-crystallography- } \\
\text { isara-sample-changer }\end{array}$ \\
\hline ACTOR (Rigaku) & $\begin{array}{l}\text { Muchmore et al. (2000), https://www.rigaku.com/en/products/protein/ } \\
\text { actor }\end{array}$ \\
\hline RoboDiff & Nurizzo et al. (2016) \\
\hline MARVIN & Cianci et al. (2017) \\
\hline Petra III P11 sample changer & $\begin{array}{l}\text { http://photon-science.desy.de/facilities/petra_iii/beamlines/ } \\
\text { p11_bio_imaging_and_diffraction/crystallography_endstation/ } \\
\text { e254458/index_eng.html }\end{array}$ \\
\hline BART & O'Hea et al. (2018) \\
\hline FlexED8 & Papp, Felisaz et al. (2017) \\
\hline FlexHCD & McCarthy et al. (2018) \\
\hline TELL & This work \\
\hline \multicolumn{2}{|l|}{ Linear axis systems } \\
\hline $\mathrm{SC} 3$ & Cipriani et al. (2006) \\
\hline ALS Automounter & Snell et al. (2004) \\
\hline SPACE & Ueno et al. (2004); Murakami et al. $(2012,2020)$ \\
\hline PAM-HC & Hiraki et al. (2016) \\
\hline
\end{tabular}

currently $24 \mathrm{~s}$, with remaining potential for improvement in trajectories and beamline integration. A so-called drymounting procedure is used, with the gripper remaining in liquid nitrogen between mounts. Robot safety is implemented in connection with the existing hutch interlock system.

\subsection{Sample storage dewar}

2.2.1. Open dewar. The sample storage dewar is a vacuum-insulated vessel, designed together with and fabricated by the company Demaco Holland bv Noord-Scharwoude, The Netherlands. It has a heating rim and is covered with a belt-driven motorized rotating lid (August Steinmeyer $\mathrm{GmbH}$, Albstadt, Germany). Rotation is triggered through the home-developed Hexiposi control system, based on a myRIO controller (National Instruments, Austin, Texas, USA), operated either remotely by the PShell control system (see Section 2.3 ) or locally by the

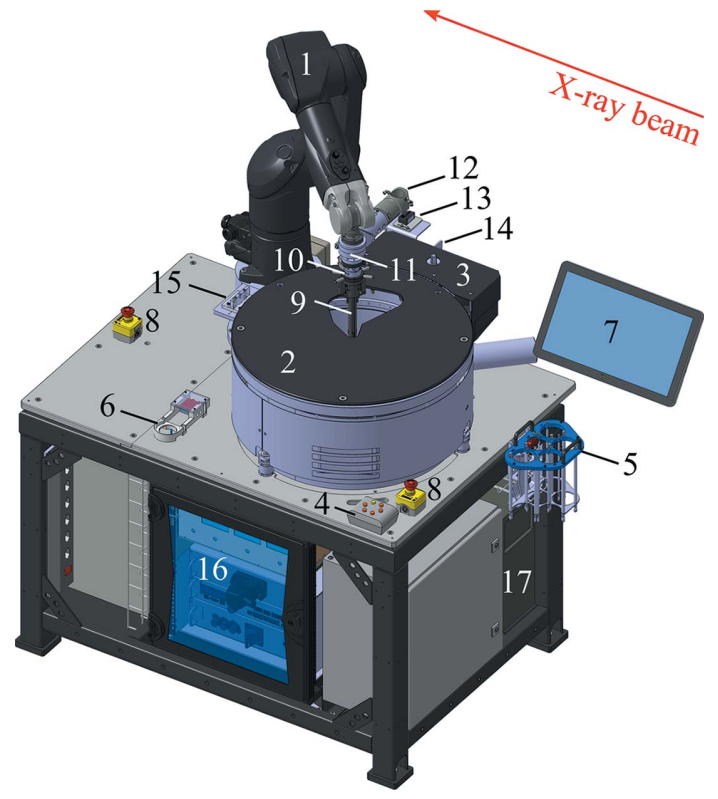

Figure 1

CAD-drawing of the TELL sample changer installed at the X06SA-PXI beamline at the Swiss Light Source. (1) Robotic arm, (2) cryogenic storage dewar with a lid, (3) lid rotation unit, (4) six-button interface of the Hexiposi controller for manual lid rotation, (5) puck loading tools, (6) puck barcode-reading station, (7) control touchscreen, (8) emergency stops, (9) sample gripper in cold position, (10) gripper exchange level, (11) pneumatic collision and overload protection (CSR50, Zimmer group, Rheinau, Germany), (12) gripper dryer, (13) gripper calibration laser sensor (ILD1320-50, micro-epsilon GmbH, Ortenburg, Germany), (14) pin barcode reader, (15) holder for beam alignment tools, (16) robot control unit, (17) PC running the PShell control system. The red arrow shows the beam axis, pointing at the sample position. All barcode readers are MicroHAWK ID-40 (Bibus AG, Fehraltorf, Switzerland). six-button manual interface (labelled 4 in Fig. 1) for puck loading. An opening in the lid plate provides access to each of the six segments of the base plate (see Section 2.2.2, Fig. 2). The formation of ice inside the dewar due to air humidity is prevented with a constant overflow of dry nitrogen gas supplied at the top of the dewar vessel [arrows in Fig. 2(a)]. The liquid nitrogen remains clean and allows for over six weeks of continuous operation.

2.2.2. Dewar base plate. The dewar base plate has six segments [Figs. 2(b) and 2(c)] of five puck positions each, offering a total capacity of 30 Unipucks (480 samples). The presence of pucks is detected using one-wire addressed mechanical switches. The modular arrangement facilitates exchange and maintenance of the segments. Pucks are fixed in position by three alignment pins around the puck [Fig. 2(b)], one having an elastic construction. At each puck position, two holes [yellow in Fig. 2(c)] on the segment and the base plate can be used for both puck detection and recognition of its type, using a camera above the dewar and LED lighting under the base plate.

\subsection{Controls}

A reliable and flexible high-level control system is implemented using PShell (Gobbo \& Ebner, 2017), a Jython-based scripting platform. Scripts are developed to implement highlevel workflows, device protocols, to interface to the Stäubli robot and to run image-processing tasks. Assisted recovery procedures are implemented by configuring safe robot trajectories between reference points and restricting volumes around these trajectories. If the robot stops inside these volumes following, for example, an emergency stop or colli- 

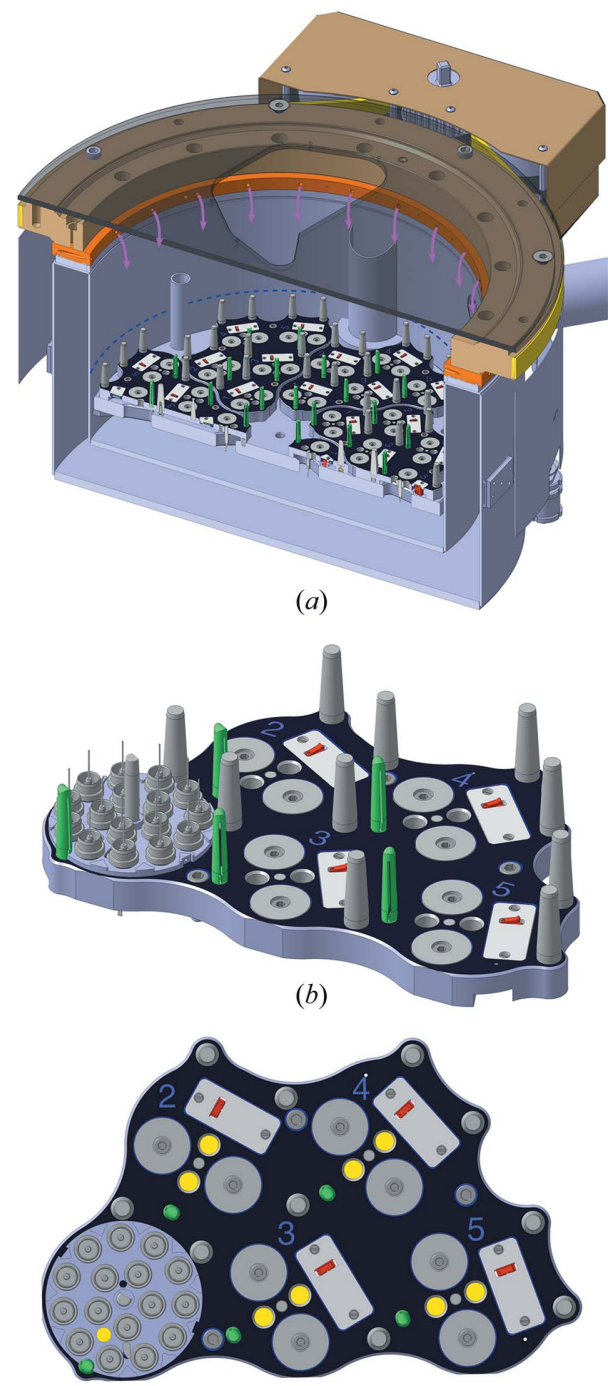

(c)

Figure 2

(a) CAD-drawing of the sample storage dewar, showing the heating rim (orange) and the lid rotation unit (brown) with a belt (yellow). The blue dashed line shows the level of liquid nitrogen, controlled by pressurebased sensors. Pink arrows symbolize the flow of dry nitrogen gas added. $(b, c)$ CAD-drawings of a segment of the baseplate, showing ferromagnetic steel rings (grey discs), alignment pins (grey), elastic pins (green) and mechanical switches (red). The LED-lit holes are highlighted in yellow. A Unipuck base is present in position 1. (b) 3D view. (c) Top view.

sion, it can resume activity by moving to the axis of the safe path and then to the nearest reference point.

\subsection{Beamline integration}

The TELL user GUI [Fig. 3(b)] is implemented in Python 3.6 using PyQt5 for the widgets. Communication with TELL is carried out via the REST interface provided by the PShell software. The TELL GUI also interacts with the beamline state machine (Wojdyla et al., 2018) to ensure that all devices are appropriately positioned for the sample changer to access the goniometer electromagnetic sample head. The TELL GUI is integrated in the beamline software system by Active $M Q$

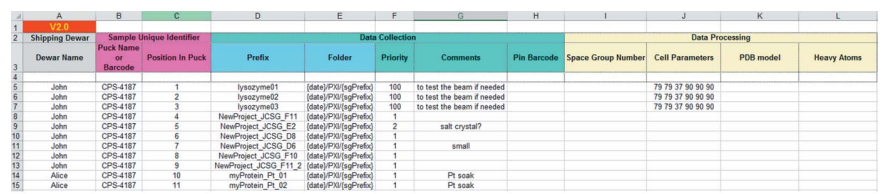

(a)

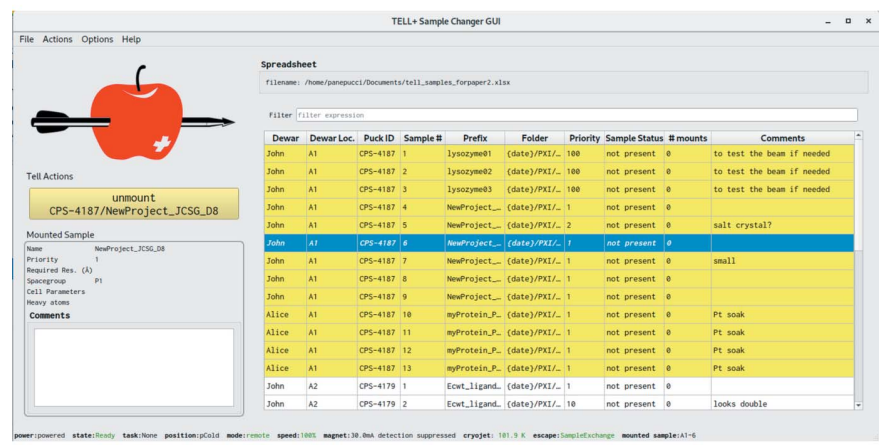

(b)

Figure 3

(a) Spreadsheet layout in Microsoft Excel format and (b) screenshot of the TELL user GUI. Brackets refer to macros for the data path and name.

messaging. Messages sent by the TELL GUI are (i) about to mount, (ii) mount finished and (iii) mounted sample information.

\subsection{User interaction}

Users first import a spreadsheet [Fig. 3(a)] with the sample information in the TELL GUI [Fig. 3(b)], then load pucks onto arbitrary positions using a puck handle and a guiding tool (labelled 5 in Fig. 1) inserted into the lid opening (Fig. S5). The lid can be manually rotated with the six-button Hexiposi interface (labelled 4 in Fig. 1). Puck position is assigned one by one, either manually on the touchscreen or automatically by scanning the barcode of the puck. Samples are selected for mounting in the TELL GUI table via a context menu [Fig. 3(b)].

\section{Outlook}

TELL is being continuously improved for sample handling efficiency, user experience and reliability. A room-temperature gripper (Fig. S6) and sample storage box with controlled environment are under development. Depending on future beamline user requirements, possible upgrades of the system could include the development of a double-tong gripper for faster sample exchange (Hiraki et al., 2008), deployment of the MiniSPINE format (Papp, Rossi et al., 2017) for increased storage capacity, and handling of crystallization plates and fixed-target supports for in situ serial crystallography (Aller et al., 2015; Martiel et al., 2018).

\section{Acknowledgements}

We acknowledge the support from Demaco for cryogenic elements, Mischa Tahedl, Marco Schneider and Stephan Maag for the development of the SwissFEL RT gripper, Andreas Keller for engineering coordination and valuable discussions, 
Bill Pedrini and the whole MX group for testing and feedback throughout the project.

\section{References}

Aller, P., Sanchez-Weatherby, J., Foadi, J., Winter, G., Lobley, C. M. C., Axford, D., Ashton, A. W., Bellini, D., Brandao-Neto, J., Culurgioni, S., Douangamath, A., Duman, R., Evans, G., Fisher, S., Flaig, R., Hall, D. R., Lukacik, P., Mazzorana, M., McAuley, K.E., Mykhaylyk, V., Owen, R. L., Paterson, N. G., Romano, P., Sandy, J., Sorensen, T., von Delft, F., Wagner, A., Warren, A., Williams, M., Stuart, D. I. \& Walsh, M. A. (2015). Structural Proteomics: High-Throughput Methods, Vol. 1261, 2nd ed., edited by R. J. Owens, pp. 233-253. New York: Springer Science and Business Media .

Cianci, M., Bourenkov, G., Pompidor, G., Karpics, I., Kallio, J., Bento, I., Roessle, M., Cipriani, F., Fiedler, S. \& Schneider, T. R. (2017). J. Synchrotron Rad. 24, 323-332.

Cipriani, F., Felisaz, F., Launer, L., Aksoy, J.-S., Caserotto, H., Cusack, S., Dallery, M., di-Chiaro, F., Guijarro, M., Huet, J., Larsen, S., Lentini, M., McCarthy, J., McSweeney, S., Ravelli, R., Renier, M., Taffut, C., Thompson, A., Leonard, G. A. \& Walsh, M. A. (2006). Acta Cryst. D62, 1251-1259.

Cohen, A. E., Ellis, P. J., Miller, M. D., Deacon, A. M. \& Phizackerley, R. P. (2002). J. Appl. Cryst. 35, 720-726.

Collins, P. M., Douangamath, A., Talon, R., Dias, A., Brandao-Neto, J., Krojer, T. \& von Delft, F. (2018). Methods Enzymol. 610, 251264.

Gobbo, A. \& Ebner, S. (2017). Proceedings of the 16th International Conference on Accelerator and Large Experimental Control Systems (ICALEPCS2017), 8-13 October, 2017, Barcelona, Spain, pp. 979-983. TUSH102.

Grimes, J. M., Hall, D. R., Ashton, A. W., Evans, G., Owen, R. L., Wagner, A., McAuley, K. E., von Delft, F., Orville, A. M., Sorensen, T., Walsh, M. A., Ginn, H. M. \& Stuart, D. I. (2018). Acta Cryst. D74, 152-166.

Hiraki, M., Matsugaki, N., Yamada, Y. \& Senda, T. (2016). AIP Conf. Proc. 1741, 030029.

Hiraki, M., Watanabe, S., pHonda, N., Yamada, Y., Matsugaki, N., Igarashi, N., Gaponov, Y. \& Wakatsuki, S. (2008). J. Synchrotron Rad. 15, 300-303.

Jacquamet, L., Joly, J., Bertoni, A., Charrault, P., Pirocchi, M., Vernede, X., Bouis, F., Borel, F., Périn, J.-P., Denis, T., Rechatin, J.-L. \& Ferrer, J.-L. (2009). J. Synchrotron Rad. 16, 14-21.

Jacquamet, L., Ohana, J., Joly, J., Borel, F., Pirocchi, M., Charrault, P., Bertoni, A., Israel-Gouy, P., Carpentier, P., Kozielski, F., Blot, D. \& Ferrer, J.-L. (2004). Structure, 12, 1219-1225.
Maire, A. le, Gelin, M., Pochet, S., Hoh, F., Pirocchi, M., Guichou, J.-F., Ferrer, J.-L. \& Labesse, G. (2011). Acta Cryst. D67, 747-755. Martiel, I., Olieric, V., Caffrey, M. \& Wang, M. (2018). Protein Crystallography: Challenges and Practical Solutions, edited by K. Beis \& G. Evans, pp. 1-27. Cambridge: Royal Society of Chemistry.

McCarthy, A. A., Barrett, R., Beteva, A., Caserotto, H., Dobias, F., Felisaz, F., Giraud, T., Guijarro, M., Janocha, R., Khadrouche, A., Lentini, M., Leonard, G. A., Lopez Marrero, M., Malbet-Monaco, S., McSweeney, S., Nurizzo, D., Papp, G., Rossi, C., Sinoir, J., Sorez, C., Surr, J., Svensson, O., Zander, U., Cipriani, F., Theveneau, P. \& Mueller-Dieckmann, C. (2018). J. Synchrotron Rad. 25, 1249-1260.

Muchmore, S. W., Olson, J., Jones, R., Pan, J., Blum, M., Greer, J., Merrick, S. M., Magdalinos, P. \& Nienaber, V. L. (2000). Structure, 8, R243-R246.

Murakami, H., Hasegawa, K., Ueno, G., Yagi, N., Yamamoto, M. \& Kumasaka, T. (2020). Acta Cryst. D76, 155-165.

Murakami, H., Ueno, G., Shimizu, N., Kumasaka, T. \& Yamamoto, M. (2012). J. Appl. Cryst. 45, 234-238.

Nurizzo, D., Bowler, M. W., Caserotto, H., Dobias, F., Giraud, T., Surr, J., Guichard, N., Papp, G., Guijarro, M., Mueller-Dieckmann, C., Flot, D., McSweeney, S., Cipriani, F., Theveneau, P. \& Leonard, G. A. (2016). Acta Cryst. D72, 966-975.

Ohana, J., Jacquamet, L., Joly, J., Bertoni, A., Taunier, P., Michel, L., Charrault, P., Pirocchi, M., Carpentier, P., Borel, F., Kahn, R. \& Ferrer, J.-L. (2004). J. Appl. Cryst. 37, 72-77.

O'Hea, J. D., Burt, M. H., Fisher, S., Jones, K. M. J., McAuley, K. E., Preece, G. \& Williams, M. A. (2018). International Conference on Accelerator and Large Experimental Control Systems (ICALEPCS2017), edited by V. R. W. Schaa, I. Costa, D. Fernandez \& Ã. Matilla, 8-13 October 2017, Barcelona, Spain, pp. 1919-1922. THPHA200.

Papp, G., Felisaz, F., Sorez, C., Lopez-Marrero, M., Janocha, R., Manjasetty, B., Gobbo, A., Belrhali, H., Bowler, M. W. \& Cipriani, F. (2017). Acta Cryst. D73, 841-851.

Papp, G., Rossi, C., Janocha, R., Sorez, C., Lopez-Marrero, M., Astruc, A., McCarthy, A., Belrhali, H., Bowler, M. W. \& Cipriani, F. (2017). Acta Cryst. D73, 829-840.

Russi, S., Song, J., McPhillips, S. E. \& Cohen, A. E. (2016). J. Appl. Cryst. 49, 622-626.

Snell, G., Cork, C., Nordmeyer, R., Cornell, E., Meigs, G., Yegian, D., Jaklevic, J., Jin, J., Stevens, R. C. \& Earnest, T. (2004). Structure, 12, 537-545.

Ueno, G., Hirose, R., Ida, K., Kumasaka, T. \& Yamamoto, M. (2004). J. Appl. Cryst. 37, 867-873.

Wojdyla, J. A., Kaminski, J. W., Panepucci, E., Ebner, S., Wang, X., Gabadinho, J. \& Wang, M. (2018). J. Synchrotron Rad. 25, 293-303. 